\title{
Review
}

\section{Wine Experiences: A Review from a Multisensory Perspective}

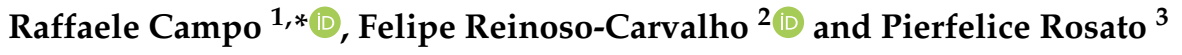 \\ 1 Department of Economics, Management and Business Law, University of Bari, 70124 Bari, Italy \\ 2 School of Management, Universidad de los Andes, Bogotà 111711, Colombia; f.reinosoc@uniandes.edu.co or \\ f.sound@gmail.com \\ 3 Department of Economics and Finance, University of Bari, 70124 Bari, Italy; pierfelice.rosato@uniba.it \\ * Correspondence: raffaele.campo@uniba.it
}

Citation: Campo, R.;

Reinoso-Carvalho, F.; Rosato, P. Wine

Experiences: A Review from a

Multisensory Perspective. Appl. Sci.

2021, 11, 4488. https://doi.org/

10.3390/app11104488

Academic Editors: Guillaume

Antalick, Lorena Butinar, Melita

Sternad Lemut and Christian Philipp

Received: 21 April 2021

Accepted: 12 May 2021

Published: 14 May 2021

Publisher's Note: MDPI stays neutral with regard to jurisdictional claims in published maps and institutional affiliations.

Copyright: (c) 2021 by the authors. Licensee MDPI, Basel, Switzerland. This article is an open access article distributed under the terms and conditions of the Creative Commons Attribution (CC BY) license (https:// creativecommons.org/licenses/by/ $4.0 /)$.

\begin{abstract}
The existing multisensory literature suggests that the combination of the different human senses in a controlled fashion during food/drink experiences can provide more enjoyment to consumers. The present research reviews recent literature relating multisensory perception with wine experiences, focusing on the interaction of the five basic senses (taste, smell, vision, touch, and sound). This is mostly being assessed from a perceptual and behavioral consumer perspective. Here, the authors report different ways in which such interactions across these senses can affect the way a wine is experienced, prior to, during, and even after tasting. The authors finish this literature review by providing some insights in the context of wine and food pairing, while also generally reflecting on potential future work. These insights may be inspirational for a diverse group of organizations working with wine. Based on such multisensory approaches, it may be possible to bring unforeseen sensations to the different wine experiences, while at the same time stressing particular sensory and/or emotional attributes.
\end{abstract}

Keywords: consumer research; food pairing; multisensory; perception; wine

\section{Introduction}

Drinking wine is among the most complex multisensory experiences, where all of the senses tend to be activated [1]. Hence, wine tasting experiences must also be studied from a multisensory perspective [2-5]. In fact, not all of the sensations that the brain associates with the experience of wine originate from the tongue [6]. Olfaction, for instance, is dominant before, and while wine is being tasted [7]. Thus, for a more precise understanding of the way a consumer experiences wine, it is crucial to consider how the senses interact prior to, during, and even after the wine tasting experience itself (e.g., with the latter potentially affecting the purchase intention, and/or willingness to pay for a food/drink product). In particular, in this narrative literature review, the authors reflect on the importance of multisensory perception during what could be regarded as the consumer journey while experiencing wine. The consumer journey (also called path to purchase) may be defined as a series of activities and events (i.e., touchpoints) that characterize the relationship between consumers and companies from the pre-purchase stage to the post-one (e.g., expectations, purchase, and post-purchase behavior). There is a recent growing interest in consumer journey research [8,9], which includes assessing cognitive, emotional, behavioral, sensorial, and social human response in such context [10]. However, current research has not sufficiently deepened on the role of multisensory perception across this path, and particularly concerning wine consumer behavior.

\section{Multisensory Perception of Food and Drink}

Food and drink experiences are multisensory in nature. Take, for instance, flavor. Flavor involves sensations beyond the taste buds [11-13]. Flavor perception usually integrates taste (the sensations gathered by the taste buds-sweet, salt, bitter, sour, and 
umami) with olfaction and possibly with elements of touch [14,15]. Some researchers suggest that flavor perception could include the integration of other sensory cues as well, such as sight and hearing [16]. Nevertheless, if one goes beyond flavor, food and drink experiences involve multiple extrinsic elements, and where the influence of signals from the different senses on flavor expectations and perception certainly go beyond the chemical senses.

Based on the above, the goal of this review work was to focus on the multisensory perception underpinning related to the experience of wine. The researchers chose concentrating on consumer tasks related to wine tasting since wine is known as a drink that strongly stimulates the senses and thus, the brain. This review was mainly based on the exploration of different databases (i.e., Science Direct, Emerald, MDPI, Wiley Online Library), while selecting those articles which clearly described how the interaction of the senses affect consumers while experiencing wine. Here, the literature that did not provide support toward the understanding of perception and behavior, from a wine consumer perspective, was excluded.

Importantly, the inclusion of additives is not usually permitted in winemaking denomination, creating a significant limitation on the ways to innovate on the flavor experience of wine via formulation. Hence, such limitations may be compensated by a better control of the sensations elicited by the extrinsic and environmental factors surrounding the experience of wine (think of lightening, background sounds, cutlery, packaging, glassware, etc.).

Below, the authors go over this multisensory literature related to wine, focusing on the interaction of four of the basic senses with the perception of a wine's taste (see Section 2 on smell, Section 3 on sight, Section 4 on touch, and Section 5 on hearing). This is mostly assessed from a perceptual and behavioral consumer perspective. In this way, they report different ways on how such interactions across these senses can be crucial to the way wine taste and flavor are perceived, while affecting the behavior of consumers prior to, during, and/or even after tasting the wine (i.e., the latter as in purchase behavior).

Most of these studies suggest that the understanding on how to better combine the different extrinsic cues that may be involved during the experience of wine, can modulate the way wine taste or flavor is perceived, adding authentic value to the product at stake, and to the corresponding consumer's journey. This review finishes by providing some insights in the context of wine and food pairing (a context that seems to be naturally explored from the practitioner's point of view, and where the interest from academia seems to be growing only recently; see Section 6). The authors also generally reflect on the relatively little related research assessing wine packaging, suggesting this as one of the research gaps that demands more careful thought in the near future (see Section 7 on future work).

The insights that are discussed here may be useful for a diverse group of organizations working with wine (i.e., wineries, shops, bars, restaurants [17]). These types of organizations usually work directly with the end-wine consumer and, thus, may be constantly looking for new ways to make the wine experience more exciting. This review suggests a number of tangible ways to engage in such excitement through the interaction of the consumers' senses. In this way, it may be possible to bring unforeseen levels of combined sensations to the different wine experiences, while stressing particular sensory and/or emotional attributes that such organizations may be looking for to deliver.

\section{Wine and Smell}

The integration of the senses of smell and taste is a fact, being such integration the baseline of what is known as flavor [7]. For instance, gustatory and olfactory stimuli converge in the same region of the orbitofrontal cortex [18,19]. In this sense, Ventura and Worobey [20] suggest that flavor sensations originate principally from the integration of these two senses, where smell becomes essential for the brain while developing food preferences, and while understanding flavor [21,22]. 
Indeed, olfactory stimuli, being processed via ortho, or retronasal, olfaction, are particularly important for the brain while processing a wine's flavor [23] (see [24], for an overview on the physiological role of olfactory cues on wine tasting). For example, Saenz-Navajas et al. [25] experimentally discussed the importance of smell in the perceived bitterness and sweetness of wine. Specifically, they analyzed 30 trained wine tasters while sorting 14 samples of wine (4 commercial and 10 altered ones) across three different conditions of odorants (A-no aroma perception through nasal occlusion; B-retro-nasal perception through orthonasal deactivation; $\mathrm{C}$-retronasal including involuntary orthonasal perception). The obtained results revealed that aroma perception can indeed modify sweetness/bitterness perception of red wines.

The role of olfaction in wine tasting certainly becomes more intriguing when the other senses get involved in the process. For example, Morrot et al. [26] suggested that wine olfactory identification may be conditioned by sight, where a white wine's odor, when colored in red, tend to be identified as having the odor of a red wine (cf. $[27,28]$ ). Parr et al. [29] also conducted a similar experiment that involved wine experts, and social drinkers (again, with white wine fake-colored as red wine). Here, wine experts were able to detect the "fake" red wines, although their assessments related to the wine's odor were more precise when the wines were served in opaque glasses (vs. clear glasses). Social drinkers, on the other hand, where significantly deceived by the fake color of the wines during their evaluations.

Heatherly et al. [30] further analyzed the relationship between wine color and odors, using Chardonnay. This study was based on wine label matching, and conducted using projective mapping which included 3D shapes and colors. Here, they found that yellow labeling for Chardonnay tends to be a best match to buttery, citrus, floral, smoky odors when compared to more vegetable-forward type of odors.

Hanson-Vaux et al. [31] further assessed the potential interactions between shapes and odors in the context of wine tasting. In particular, 25 young participants had to rate, on Likert-scales, how well they thought 20 different odors would match with specific shapes. The findings in this study revealed an association between lemon and pepper odor with angular shapes, and between raspberry and vanilla smell with more rounded shapes. Hummel et al. [32] also demonstrated that the shape of the glass of wine can have a significant impact on the way tasters experience the smell of wine. In the latter study, the smell of wine was perceived as better, and more intense, when tasted in bulbous-shaped glasses [33-35]. Cliff [33] carried-out an experiment involving 18 blindfolded participants who had to evaluate aroma and color intensities of red and white wines when served in three different types of wine glasses as well (ISO standard, Riedel Chardonnay ${ }^{\mathrm{TM}}$ and Riedel Burgundy ${ }^{\mathrm{TM}}$ types of glasses). This study suggested that glass shape, and in particular the cuppa-diameter and cuppa-opening ratio, can affect how intense a wine's flavor is perceived (with highest intensity ratings being reported via the Burgundy ${ }^{\mathrm{TM}}$ glasses, and the lowest via the Riedel Chardonnay ${ }^{\mathrm{TM}}$ ).

The relationship between the taste and smell of wine was also recently investigated at different altitudes [36]. Here, two different wine tasting experiences were organized involving 22 participants. First, they tasted the wine on board of an aircraft flying at standard cruising altitude. Second, the same participants tasted the same wine at ground level. The latter results showed no differences in flavor and liking ratings between the two different latitudes (cf. [37], who suggested that changes in atmospheric humidity, and pressure, may have a significant impact on olfactory perception).

In summary, whereas there is a clear integration between taste and smell during wine tasting, the most exciting multisensory effects seem to arise when other senses get involved, such as sight and touch. On the one hand, concerning the color of wine, it would be plausible to assume that the little variation of color types across most commercial wine categories (i.e., red vs. white variations, with some rose and green wines in between) tend to condition most consumers toward strong color-smell associations. 


\section{Glass Shape and Smell}

When it comes to shape and smell, the effect that a wine's glass shape seems to have on the perceived flavor intensity point toward a multisensory scope, for example, via the bouba-kiki effect (also sometimes referred as the maluma/takete effect). Such effect originally suggested the existence of specific associations between sound and the visual shape properties [38]. Here, it is argued that most people tend to prompt a strong preference to pair jagged/angular shapes with "kiki/takete" sounds, and rounded shapes with more "bouba/baluba" types of sounds (see Figure 1).

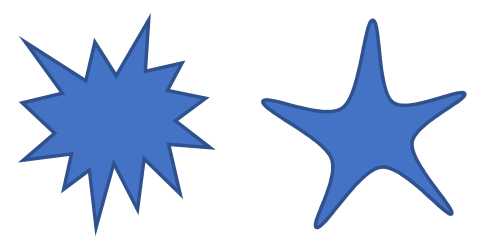

Figure 1. A visual example on the Bouba-Kiki effect [38], where the right image represents a rounded shape ("bouba/baluba"), and the left image represents a jagged/angular shape ("kiki/takete").

The usage of this concept has further evolved overtime, gaining relevance in the context of multisensory tasting experiences as well. For instance, angular shapes have been shown to be more naturally associated with specific taste/flavors (think of acidity, piquancy, or rough/hard textures/mouthfeel), when compared to rounder shapes that are usually more naturally associated with sweetness and/or smoother types of sensations (e.g., [31,39]). However, the interaction between a glass shapes and wine odor could also be explained by [40], who emphasizes on the role of oxygen on wine tasting, particularly suggesting the ISO wine glass shape as probably the best one for wine tasting, because of the lowest wine oxygenation that it generates (as compared to any other kind of wine glass shape). Nevertheless, glassware can certainly have qualitative implications on the experience of wine consumers. In particular, a better appreciation of the wine's flavor, including more pleasant sensations triggered by a glass shape, may positively enhance the overall wine tasting experience (e.g., [32]; see [41,42], for an overview on sensation transference effects). In brief, when considering all of the senses as main sources of sensations while tasting wine, one should take into consideration the fact that consumers have the ability to transfer sensations and emotions across the senses. Therefore, when thinking about the different ways in which to approach the different multisensory information that may be part of an experience with wine, the question of whether such sensations may elicit specific emotions, should be at stake. The latter may also consider how such emotions add value to the whole concept behind the corresponding wine experience.

\section{Wine and Sight}

If one considers the relevance of each sense during the experience of drinks, such as wine, taste and smell would be the most important ones, immediately followed by sight. In other words, in several of the studies discussed in this review, a kind of hierarchy is most likely being revealed, concerning the role that each sense may have during the experience of wine (as in sensory dominance; e.g., [43,44]). Such sensory dominance may be related, but not necessarily dependent, on how much the sensations in question may be integrated-or not-at the cognitive level $[45,46]$. In fact, such dominance may be more dependent to the main objective that the specific experience is looking for to affect, and the importance of each particular sense in such context.

In this sense, it has been shown that the color of the wine can elicit intriguing effects on the experience of wine, including some rather interesting qualitative attributes, such as the ability to modulate its perceived freshness (e.g., [47]). A long time ago, Pangborn et al. [48] verified that pink-colored wines tended to be perceived as sweeter, when compared to white, light red, dark red, and/or light brown-colored wines. This type of studies became more recurrent in the recent decades (i.e., [49-52]) [49], for instance, studied how the color 
of wine affected its flavor, while asking consumers to rate different sensory attributes of the same Californian Chardonnay, presented in three different colored versions (original white, fake rosé, and fake red). These findings revealed significant differences concerning the perceived fruitiness, fullness, complexity, and maturity of this wine across the different colored presentations (see also [50], for a correlation between a wine's color and flavor intensity). On the contrary, Valentin et al., 2016, verified that a wine's color does not seem to be a driver for its quality - at least when assessed by French and New Zealand wine professional tasters.

The effects that color can trigger in the experience of wine are not limited to the color of the wine itself, but they can also be explored through other means, such as labeling. For example, Lick et al. [53] suggested that red and black labels can elicit expectations toward a tangy wine flavor, whereas orange and red labelling seems to trigger more "fruity" and "flowery" gustatory expectations for the same wine [54]. The impact of environmental visual cues in wine tasting has also been analyzed from different perspectives. Variables such as the color of an ambient where wine is being tasted, can impact its perceived flavor [55]. In the latter study, a white Riesling was reported as tasting better in blue and red lighted environments, when compared to when tasted under the influence of white or green lightening (cf. [56,57]).

Besides color, another important visual cue to be considered in the experience of wine is glass-shape [33,58-61]. Wan et al. [61], for instance, showed that Chinese and North-American consumers, while rating photos of different alcoholic drinks served in various glasses, would prefer, and pay more, for the same wine, when served in glassware considered as congruent (say, a typical stemware type of wine glass). The latter was reported in comparison to their preferences and willingness to pay for the wine when served, e.g., in a beer mug (see [62], for similar results covering different drinks). Meanwhile, Pechey et al. [63] found a link between glass size and wine consumption. Specifically, three glasses of different sizes, but similar shape, where used in an experiment conducted in a restaurant-bar in Cambridge, Great Britain. Here, an increase in wine purchases was observed when the wine was served in the larger glass. Note that, back in Section 2, the role of glassware on the experience of wine was already discussed when it comes to wine and olfaction, and will also be shown as having further interesting implications concerning the sense of touch, below, in Section 4.

Besides the aforementioned visual aspects related to the experience of wine, one could also think about the effects that the appearance of the container of the wine could further bring to the wine experience. In this sense, one could immediately think of the stereotypical bottle of wine, and corresponding closure. Accordingly, Reynolds et al. [64] assessed the role of the different bottle closures in the sensory experience of wine among American consumers. The latter findings revealed that those wine bottles closed with a natural cork had the highest rate in terms of appearance, taste, and quality, when compared to those wine bottles sealed with a synthetic cork, or with a screw-cap. Likewise, Barber et al. [65] verified that the type of bottle closure can affect consumers' purchase decisions. In particular, they compared, via an on-line questionnaire, the relevance of wine bottle closures (i.e., natural cork, synthetic cork, and screw-cap) among baby boomers and millennials consumers. These findings suggested that millennials are more likely to choose a wine bottle sealed with a natural cork as a gift for special occasions, as compared to baby boomers that do not seem to be so "picky" in a similar context. Likewise, Marin et al. [66] conducted a similar study where the wines were presented to different groups of participants, first, without revealing the closure system, and second, with details on the corresponding closure. In the first experiment of this study, a Chardonnay was liked less after the participants were informed that the bottle was sealed with a synthetic cork, and with a screw-cap, when compared to those participants that learned that such wine was sealed with a natural cork. Similarly, in the second experiment, quality scores for Merlot-wine were higher for those who were informed that the bottle was sealed with a natural cork. Finally, Marin et al. [67] 
concluded that natural corks tend to be framed as synonyms of quality for wine consumers while, e.g., affecting their purchase intention.

Now, with taste, smell, sight, and some notes of touch converging, it seems that the average consumer tends to frame specific associations across the senses as more congruent than others while experiencing wine. For example, part of the literature so far reviewed suggests that certain colors of wine elicit specific flavor notes. Hence, while exploring different multisensory wine perspectives, it may be of importance to look for crossmodal correspondences, which refer to the tendency for the brain to preferentially associate certain features or dimensions of stimuli across the senses [68,69].

Moreover, wine seems to taste better for the majority of consumers when served in its typical glassware, and while being poured via a wine's bottle previously sealed with a natural cork. Concerning the latter, while exploring sight during the design of a wine experience, it may also be crucial to ponder that certain visual aspects that may be positively shaping such experience tend to be semantically conditioned (as in semantic congruence). Semantic congruence refers to the ability of combining signals from the different senses as a function of a common identity, or meaning (as in semantic congruence; [70-72]). Therefore, the pursue for semantic congruence in this context may help better communicating a particular value proposition.

\section{Wine and Touch}

As already denoted in the previous sections, touch-sometimes also referred to as somatosensory, tactile, or haptics sensory system-is a sense that has a relevant role during wine experiences. While drinking wine, touch tends to be mostly activated through glassware/packaging/container interactions, as well as via mouthfeel. Several studies concerning wine glassware-hence, relevant for this section-were already introduced previously (e.g., [32-35,58-61,68]).

In general, researchers have also assessed the way consumers are influenced by a beverage's packaging/container material, but not necessarily in the particular context of wine (e.g., [73,74]). In [73], for instance, it was verified that the perceived "firmness" of a container affects specific aspects of the experience of a beverage. In this case, water was perceived as lower in quality when consumed in a "flimsy" cup, as compared to when consumed in a cup considered as "firmer".

From a multisensory point of view, there seems to be a gap in the literature concerning the role of packaging/container in the experience of wine, where a considerable amount of studies focusing on such effects have not yet emerged in the context of consumer behavior. This may be due to the fact that most wines are commercialized in a pretty much standardized glass-shaped bottle. Nevertheless, there are two intriguing relationships between touch and wine, previously reported, that could somehow fit in the context of packaging/container assessment. First, Piqueras-Fiszman and Spence [75] reported that consumers tend to positively correlate the weight of a wine's bottle with the price of such product. Second, in a more recent study conducted by [76] the participants were subdivided in two groups, and tasted red wine while manipulating different tactile materials (sandpaper or velvet, depending in which group they were assigned to). Such assessment was subdivided in two steps, flavor-wise speaking (first, ratings focused only on olfactory stimuli, while the second step focused on sensations elicited by taste only). The obtained results suggest that the wine was perceived as sweeter and fruitier to the nose while touching the velvet, as compared to the ratings related to the sandpaper, and this may be due to a general preference of consumers toward smoother textures [77].

With the above being said, an opportunity to deepen on the multisensory effects of packaging/container in the experience of wine could emerge. Even though commercial wine bottles are mostly standardized in terms of material and shape, there are, in fact, wines being commercialized in Tetra Pak containers (https://tinyurl.com/wine-tetrapak, accessed on 2 March 2021), cans (https:/ / tinyurl.com/garrafao-vino, accessed on 2 March 2021), and gallons that are usually enclosed by plastic/rope nets (https:/ tinyurl.com/ 
wine-in-cans, accessed on 2 March 2021). The three aforementioned types of containers would most likely trigger different visual and somatosensory sensations, when compared to a typical glass bottle of wine. Think, for instance, on the fact that cans are much more susceptible to transfer temperature via touch, when compared to glass or plastic. Also, there is the fact that the shape of a Tetra Pak container is usually significantly more angular when compared to the rounder shapes elicited from a wine's bottle (think of the bouba-kiki effect). In any case, there is also the potential case that wine promoted via can, Tetra Pak, and/or bottled in a gallon, might be immediately framed as in a cheaper/lower-quality category, or perhaps as a kind of incongruent packaging experience, when compared to when promoted via the most common bottling.

Moving beyond glassware and packaging, mouthfeel, as the name highlights, usually refers to the tactile sensations generated inside the mouth during consumption. Regarding wine, mouthfeel usually has an active role on sensations associated to the experience of a wine's temperature, astringency, body/viscosity, prickling, sparkling, and even burning sensations, such as hotness [78]. Jones et al. [79], for example, focused on how different wine formulas can affect the way wine flavor notes, that may not be directly related with such differences in formulation, are experienced. In this study it was found that glycerol contributes to a greater perceived body/viscosity, whereas ethanol and other volatile compounds can enhance the perceived hotness. However, in the absence of polysaccharides, and low volatiles/glycerol, such sensations related to hotness tend to be reduced, even if the alcohol percentage remains at similar level. Ethanol also seems to enhance perceived bitterness, whereas glycerol has an opposite effect. On top of that, ethanol triggers sensations related to the dryness of the palate.

The effect of a wine's pouring temperature prompt by mouthfeel was tested by [80] as well, in a study involving 32 panelists. In this assessment, they considered three pouring temperatures for, both, red and white wines (14-18-23, and 4-10-18 degrees Celsius, respectively). Results related to the white wines revealed, for example, that the further its pouring temperature decreased, the less panelists perceived the intensity of the white wine's aroma. With regards to red wines, the researchers reported a minor change in aroma perception when comparing the wine at the lowest vs. the highest experimental pouring temperature. Meanwhile, Cliff and King [81] also found that the fruity component of wine is more evident at higher pouring temperatures.

Ref. [82], while comparing a wine's astringency vs. its body, via mouthfeel, reported that an increased astringency negatively affected how much a consumer liked the wine, while evoking ratings related to negative emotions. On the other hand, an increased perceived body had an opposite effect on the experience of wine. In this sense, it may be of relevance as well to reflect on the fact that a wine's body might not only be triggered by mouthfeel sensations-even if naïve consumers may believe so-but it may be a more complex perceptual construction, including sensations related to flavor intensity [83,84]. In summary, the somatosensory sensations elicited by mouthfeel, as compared to the other sensations being discussed in this review, are the ones perhaps more directly related to the particular characteristics of a wine's formula.

\section{Wine and Hearing}

When thinking on the role of the five basic senses in the experience of wine, hearing has perhaps the least obvious role and, thus, is the sense that was so much explored in the past [85]. In the recent decades, however, researchers have been proving that what we hear can significantly affect the tasting experience of foods and drinks, including wine (see [86,87], for an overview). In the 1990s, a couple of pioneer studies were conducted focusing on how the music that one listens while shopping can affect our purchasing behavior for wine. In particular, Areni and Kim [88] found that classical music can induce consumers to spend more money by acquiring the most expensive wine choices available, while $[89,90]$ revealed that music can bias the way consumers select wine. Specifically, North et al. [90] showed a congruency between the type of music, and the choices con- 
sumers make over wine. In this study, four French and four German wines were displayed in a supermarket in the United Kingdom, where a flag helped indicate their provenience. Such shopping experience was further enhanced by French and German music, being played on alternate days. Interestingly, when French music was playing, French wines outsold the German ones, and vice-versa.

The influence of type of music on the experience of wine was also assessed by [91], but this time with a focus on flavor perception. Here, the participants were subdivided into three main groups, while tasting a Merlot, and a Chardonnay, and at the same time while listening, with headphones, to pop music (a Justin Timberlake song), classical music (Mozart), or no music at all. The latter findings highlighted that the participants perceived the Chardonnay as sweeter when listening to Mozart. The Merlot, on the other hand, was perceived as less alcoholic under the influence of the pop music.

Intriguingly, the impact of music on wine tasting has been explored via a prototype of augmented glassware as well, where a wine glass equipped with sensors that were able to detect different gestures made by the consumers was built ([92]; see also https: / / www.cienciae-vinho.com/2019/06/02/musical-wine-glasses/, accessed on 2 March 2021). When this glass was used in a piano bar filled with red and white wines, and while used by consumers when drinking wine and listening to high vs. low-pitched sounds, it revealed that low pitched sounds gave more "weight" to the wines, and were deemed more congruent with the white wine. On the contrary, high-pitched sounds were judged as more congruent with the red wines. The same glass was also used in a wine bar in the city of Buenos Aires (Argentina), revealing that most of the consumers perceived an intensified wine acidity when listening to high-pitched and dissonant sounds.

In fact, in the last 10 years, such type of research has been booming across different foods and drinks, and where the particular influence of sounds in the experience of wine is being analyzed from more detailed and sophisticated perspectives than ever before (e.g., [86,93-99]). North [93], for instance, gave to the participants a glass of red and white wine, to taste, in one of five rooms, where four different kinds of music were present (powerful/heavy, subtle/refined, zingy/refreshing, and mellow/soft, respectively), along with a room with no music. While rating how much the participants liked the wines, and the music, referring to the same aforementioned musical attributes, there was a clear coherence between the kind of music, and how the attributes were associated to the wines.

A multisensory study involving wine tasting, sight, and hearing, was further conducted by [94]. Participants had to rate a red wine while standing in four different environments where lights and music were changing. These results highlighted that, in the case of green lightening, and "sour" music, the wine was perceived fresher and less intense, whereas the same wine was liked more when the lights of the room were red, and the music was "sweet." The effects of music congruency on a wine's flavor were also analyzed by [99]. In this study, most participants, when pairing two different songs (Debussy's Jardin Sous la Pluie, and Rachmaninoff's Vocalise), with two different wines (an Argentinian Malbec, and a French Sauvignon-Blanc), described similar better matchings. Here, they also reported that both wines were perceived fruitier while listening to Rachmaninoff, and more acidic while listening to Debussy. Also, more recently, Wang and Spence [100] showed that different soundtracks affected the way wine experts rated the perceived body, balance, length, and likeness for the wine (as in sonic seasoning; [101,102]. When one talks about sonic seasoning, one is referring to sounds produced, or chosen, in order to trigger specific perceptual and/or emotional effects in food/beverage experiences. Sonic seasoning is a concept derived from the framework of crossmodal correspondences (e.g., [103,104]; see [99], for an overview).

In this sense, Burzynska et al. [105] recently focused on the impact of low frequency sounds on wine perception as well. Specifically, two wines (a New Zealand Pinot Noir and a Spanish Garnacha) were tasted in silence, vs. with $100 \mathrm{~Hz}$, and $1000 \mathrm{~Hz}$ frequency tones. Results highlighted that the Pinot Noir was perceived more full-bodied when participants were listening to $100 \mathrm{~Hz}$, as compared to while listening to $1000 \mathrm{~Hz}$, and when in silence. 
The $100 \mathrm{~Hz}$ tone also had an impact on the Garnacha's taste, which was perceived more aromatically intense, as compared to when tasted under the effect of the $1000 \mathrm{~Hz}$ tone. Intriguingly, [106] also explored the impact of changing the music while tasting wine. In particular, when the music was shifted from a "sweet" to a "sour" song, the participants tended to perceive the wine as predominantly sour. Vice-versa, when the music changed from "sour" to "sweet," the predominant perception was the sweet one.

Not only the background soundscapes can affect the way the flavor of wine is experienced. As a matter of fact, Spence and Wang [107] assessed whether different sounds of wine bottles being opened could affect wine ratings (in this case, comparing the sound of a popping cork vs. the sound of a screw-cap). The obtained results suggest that the sound of the cork generated higher ratings in terms of the wine's quality, and more appropriateness for a celebratory occasion/mood. The latter study somehow takes us back to Section 3, where visual cues associated to natural corks tend to be framed by wine consumers as synonyms of quality (i.e., $[66,67])$.

So far, the authors have discussed the multisensory literature related to wine, mainly focusing on the interaction of the five basic senses. Here, the authors have been showing that each sense can bring different insights to the experience of wine prior, during, and even after tasting it. By now, it is possible to foresee different ways to combine each sense in order to enhance the multisensory experience of wine. Intriguingly, some of these effects are not so much about adding sensory cues, but rather understanding how each sense can, let us say, give specific meaning to a particular objective related to a wine experience. Here, it may be of importance to remind that it is not always about adding layers of sensory information, since they may end-up guiding the experience to an undesired sensory overload [108]. By adding too many signals from the different sensory inputs, without meaning and/or without clear objectives, one may arrive at the opposite effect, by adding noise to the consumer's journey. Such sensory overload can also be understood from the congruent vs. incongruent perspective. For instance, if the signals from the different senses do not align (i.e., being framed as incongruent by the receiver), this may derive in a less fluid cognitive process and, again, potentially overloading the senses. In fact, sound is crucial in this sense, since it can be regarded as an unpleasant stimulus, if not properly controlled and/or induced. For instance, it has been argued that, when music is too loud, or when there is sound regarded as noise by the listener, what one hears can negatively impact the tasting by masking the ability to clearly perceive the details of the different flavor attributes at stake (as in, e.g., crossmodal masking; see [96,109].

With the above being said, in the next section, the authors move toward reflecting on how these broad possibilities for the enhancement of a wine experience, through the senses, can be further expanded when combined with other foods. Wine and food pairing, while greatly appreciated and explored from a practitioner's perspective overtime, seems to be gaining attention only recently in academia.

\section{Wine and Food Pairing}

The role of the different senses, and how they interact during a wine experience seem to have a steady growing team of researchers looking for insights. In parallel to the aforementioned research, the interest on the better understating on wine and food pairing, from a scientific perspective, is growing recently (see [110], for a very recent general review on this topic across general foods and drinks). Wine and food pairing is usually framed as the experience where a food or a drink, combined with wine, creates a new set of sensations (cf. Spence).

Such an idea should not come as a surprise, since wine is usually regarded as a culinary delicacy due to its flavor complexity, being an important added value in gastronomy (e.g., as a tool for marinating). In this sense, a better understanding of a wine's "complexity" [111] might also be of relevance while, e.g., reflecting on the possibilities of building meaningful multisensory experiences with different foods and wines [112]. By discussing the different meanings of the term "complexity", when referring to wine, there is the challenge to land 
into a simplified and unique definition. Spence and Wang [111], for instance, argued toward the usage of the term "complex" when the taste of wine elicits a number of distinct, yet harmoniously balanced, attributes that can be experienced over the course of a single, but prolonged, mouthful experience. Here, they also suggest that another understanding of a wine's complexity could be related to the lifespan of the wine, during bottle aging (i.e., the older, the more complex).

Wang and Spence [113] also underline how a wine's complexity may be conceived in terms of the number of flavor attributes perceived by the consumer (e.g., the more attributes it is possible to disentangle while tasting, the more complex the wine tends to be framed). Wang and Spence [113] also suggested that complexity may be based on the temporal evolution of the wine's flavor while inside the mouth, or even in terms of more holistic, including individual/subjective overviews. Intriguingly, while discussing these issues, they explored a wine's complexity involving 18 social drinkers, who rated eight wines, and with each one of these wines representing different pre-defined frameworks of complexity. These findings unveiled a general positive correlation between a wine's complexity and perceived liking/quality, while not necessarily correlating its complexity with price, or by the numbers of attributes perceived, while describing its flavor.

Now, when it comes to wine and food pairing, Spence and Wang [112] further aimed toward a reflection more focused in the physical complexity of such pairing, which could be interpreted as a set of different ingredients/elements combined from both, wine and food being paired, giving birth to a novel and "complex" set of physical stimuli. In this sense, Nygren et al. [114] studied the interaction between Chardonnay and two different versions of Hollandaise sauce (lower and higher fat versions), finding that both sauces reduced a wine's perceived intensity and sourness. Nygren et al. [115] also studied the impact of blue mold types of cheeses (Swedish Bredsjö Blå, and French Roquefort Société) on the flavor of different types of dry white-wines. Here, both cheeses mostly decreased the perceived sourness, "appleness" (as in sensations that resemble the flavor of an apple), "citrusness," and "oakness" of the wines, whereas the bitterness and sweetness of the wines were not significantly affected. The same scholars also evaluated the opposite, which means the effect of white wines on the flavor of the two aforementioned blue mold cheeses (see [116]). Here, they found that, after tasting wine, buttery and woolly sensations related to the Swedish cheese, along with saltiness and sourness ratings on the French cheese, decreased.

Similarly, Madrigal-Galan and Heymann [117] explored the interaction between different combinations of eight wines and eight cheeses, with wine experts. This study revealed that, tasting cheese prior to tasting wine, can affect a wine's flavor description, where the ratings related to the wine's astringency, bell-pepper and oak notes tended to decrease. Hedonic sensations were also analyzed by [118], in a $2 \times 2$ design combining two wines (Ruby Port and Sauvignon blanc), and two different types of foods (goat cheese and dark chocolate). After participants tasting different combinations of such foods and wines, these results revealed that, when a food is liked a lot (in this case, the chocolate), it may reduce the liking ratings of the wine that was being paired with such food. The relevance of food liking during wine tasting has been recently underlined by [119] as well. In this assessment, they observed that the most liked food-wine pairings were driven by the food that consumers preferred, where in those food-wine pairings framed as the most appropriate ones, the ratings concerning the flavor intensity of the whole experience increased.

In this sense, Foodpairing ${ }^{\circledR}$ (https: / / www.foodpairing.com/; accessed on 1 March 2021), a food-tech company, developed an intelligent tool in which an in-house ingredient pairing algorithm is able to suggest uncommon food and beverage pairings. Such pairings are not necessarily culturally and neither historically oriented, but rather based on current scientific knowledge that partly relies on rationale related to multisensory perception. As a matter of fact, the starting point of this pairing process is based on the analysis of food aromas that are framed as relevant for the sense of smell. Like this, when a food and beverage share a particular aroma, the algorithm suggests that they are likely to outcome a "good" pairing. As already observed by [110], this tool, which was developed 
through the interaction between chemists and computational gastronomists, is mainly about mapping similarities across flavor molecules. Such a solution can be certainly useful while innovating on the way unforeseen food and wine pairings can be built based on the different senses. In other words, there are many opportunities to be explored when it comes to wine and food pairing. Such opportunities also tend to gain momentum when disentangling the different multisensory sensations elicited during wine tasting, combined with the different multisensory sensations prompted by the food that is being tasted with the wine (as in a kind of multisensory wine food pairing matrix).

\section{Final Remarks and Future Works}

A better understanding of the rationale behind multisensory perception, and its role in tasting experiences is becoming crucial in order to further innovate in the context of, for example, food marketing. Here, wine is certainly playing a leading role, most likely due to its versatile nature, sophistication, and culinary added value (and, of course, by the strength of the wine industry, which is a certain drive toward constant innovation). As shown across the above sections, all of the senses can be actively involved prior, and during wine tasting, where the interactions of the senses can significantly affect specific aspects of the experience of wine. Such specific aspects can be at the perceptual and/or emotional levels, which also end-up affecting, e.g., purchase variables related to wine consumption. The insights summarized in this literature review are certainly useful concerning managerial decisions related to wineries, wine shops, and/or restaurants/bars, as they would help providing innovative ways to directly engage with customers.

In the following Table 1 , the authors summarize strategical ways to rethink the way a wine experience can be designed from the multisensory perspective that has been discussed across this literature review.

Table 1. A summary suggesting how the wine experience of consumers can be strategically designed from a multisensory perspective.

\begin{tabular}{|c|c|c|}
\hline Rationale & Application & Examples \\
\hline $\begin{array}{l}\text { Crossmodal Correspondences: The } \\
\text { tendency for the brain to } \\
\text { preferentially associate certain } \\
\text { features or dimensions of stimuli } \\
\text { across the senses }[68,69] \text {. }\end{array}$ & $\begin{array}{l}\text { Looking for crossmodal } \\
\text { correspondences across the different } \\
\text { senses can be useful in order to } \\
\text { further customize and/or enhance } \\
\text { the multisensory experience of wine. }\end{array}$ & 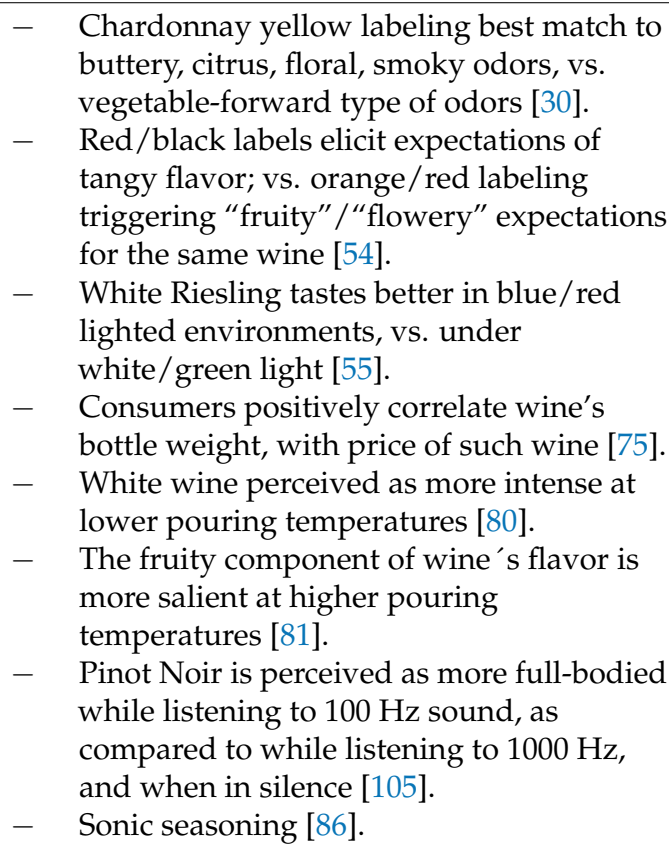 \\
\hline $\begin{array}{l}\text { Sensory Dominance: Hierarchy } \\
\text { concerning the role that each sense } \\
\text { may have during a certain experience } \\
\text { (as in sensory dominance; e.g., }[43,44] \text {. }\end{array}$ & $\begin{array}{l}\text { If one considers the relevance of each } \\
\text { sense during the experience of wine, } \\
\text { taste and smell would be the most } \\
\text { important ones, followed by sight, } \\
\text { touch, and hearing. }\end{array}$ & $\begin{array}{l}\text { - } \quad \text { Aroma perception modulates } \\
\text { sweetness/bitterness of red wines [25]. } \\
\text { - The assessment of a wine's odor usually } \\
\text { conditioned by sight [29]. }\end{array}$ \\
\hline
\end{tabular}


Table 1. Cont.

\begin{tabular}{cc}
\hline Rationale & Application \\
\hline & \\
Semantic congruence: Ability of & The pursue for semantic congruence \\
combining signals from the different & in wine experiences may help better \\
senses as a function of a common & communicating a particular \\
identity, or meaning [70-72]. & value proposition.
\end{tabular}

Sensation transference: Ability to transfer sensations and emotions across the different senses [41,42].
Pleasant sensations coming from the different senses can affect the overall experience of wine, and vice-versa.

- A red-colored white wine's odor tends to be identified as the odor of a red wine [28].

- Pink-colored wines tend to be perceived as sweeter/more-fruity, when compared to white, light red, dark red, and/or light brown-colored wines [48,49].

- Wine tends to be preferred and regarded as more expensive when served in congruent glassware [61].

- Wine taste better and is regarded as having higher quality for the majority of consumers when served in its congruent glassware [32], and while being poured via a wine's bottle previously sealed with a natural cork e.g., $[64,66,67]$.

- A wine's color does not seem to be a driver for its perceived quality [51].

- Wine is perceived as sweeter and fruitier to the nose while touching velvet, vs. touching sandpaper $[76,77]$.

- The sound of a cork generates higher ratings in terms of a wine's quality, and more appropriateness for a celebratory occasion/mood [107].

Sensory overload: Adding too many signals from the different sensory inputs, without meaning and/or without clear objectives [108].

Non-arbitrary mapping, such as the bouba-kiki effect [38], which suggests that most people tend to prompt a strong preference to pair jagged/angular shapes with "kiki/takete" sounds, and rounded shapes with more "bouba/baluba" types of sounds.
It is not always about adding layers of sensory information during the experience of wine, since they may end-up guiding such experience to an undesired sensory overload.
Angular shapes have been shown to be more naturally associated with specific taste/flavors (think of acidity, piquancy, or rough/hard textures/mouthfeel), when compared to rounder shapes that are usually more naturally associated with sweetness and or smoother types of sensations.
- To loud music/noise can negatively impact tasting by masking the ability to clearly perceive flavor details [96,109].

Moreover, wine brands could benefit of these results while designing their physical and virtual points of sales, where consumers may be nudged via customized multisensory stimulation. In this sense, let us think of color, smell, sound, and/or different foods, as elements that can help creating unforeseen experiences that may be even further emphasized during special events and/or fairs.

As proved in this report there is in fact a steady growing body of research approaching from many different perspectives the multisensory experience of wine. Nevertheless, to our knowledge, research related to the material and shape of wine containers/packaging/bottles, as well as more sophisticated studies assessing multisensory food/wine and wine/food pairing are, both, great areas for new discoveries and extensive exploration. Concerning the latter, so far, most of the existing literature is limited to cheese-wine pairing. Hence, there is clear room for further research on, say, starchy, sea, pickled/preserved, as well as different sweet type of foods, (i.e., chocolate), while being paired with wine from a multisensory perspective. All the aforementioned food products are already being constantly served with wine across general HORECA industry (HORECA, as in hospitality, restaurants, and catering). Since wine is a flagship in culinary 
and gastronomy, a more detailed approach on the multisensory effects of wine on the tasting experience of different foods, and even drinks, may also be interesting and useful to add value to the way in which a consumer responds to a brand. Global liquor brands, such as Jägermeister, are already betting on these ideas as part of their brand positioning (e.g., https:/ / www.jagermeister.com/en/taste-remastered; accessed on 3 March 2021). Entrepreneurs and developers are also at the moment offering solutions that are supposed to intelligently create musical playlists for wine (http:/ / winelistening.com/; accessed on 3 March 2021).

Some of the results summarized in this review may eventually become more precise with the inclusion of state-of-the-art technology. From a neuroscientific perspective, for example, novel insights will be uncovered as long as biometry and electrophysiology continue to be included in wine assessments (as they are already being assessed with, e.g., chocolate and ice-cream; see [120,121], respectively). Researchers are starting to wonder how the digital-retail wine experience can be optimized via AR/VR solutions as well (e.g., [122,123]; see [124], for a general view on state-of-the-art digital sensory marketing). Nowadays, the latter seems to grow in importance as one tends to consume more and more via e-commerce platforms, and where the virtual version of a product such as wine is, most of the time, the single contact that the consumer has with such product during the purchasing decision process. A food/drink properly presented via e-commerce may be key, for example, to nudge consumers toward new products and new multisensory experiences [125].

The ideas discussed in this review may also be of relevance from a well-being perspective. Consumers seem to demand healthier and more sustainable life-styles, where food and drink choices can be determinants during such kind of pursue. Here, a successful presentation of a wine can also be critical for, let us say, more effectively communicating specific health-related information related to its moderate consumption [126-128]. To this end, future research could also consider to deepen on how the use of different additives during wine formulation affect its tasting experience and consequently the market receptivity (see [129], for a study based on wine consumers' acceptance of additives). Note that, as mentioned above, the latter may also have further legal implications, since flavor additives are usually not legally permitted winemaking aids, so their addition to wine may force the final product to be promoted in a different category (as in wine derived products).

There is certainly room for future research work related to how to better communicate the country of origin of a wine via the different senses. Particular attributes assigned to a wine, by the consumer, have been already shown to be influenced by the wine's country of origin (see [130], for an analytical study on the impact of the country of origin on the consumer's mental representation of wine). From this perspective, wine multisensory experiences may help toward a better understanding of the differences that exist across wine producers considered as traditional (e.g., Italy, France, Spain and Chile), versus less traditional ones (e.g., Denmark and Switzerland), and how such differences may influence the end consumer. Novel research could also focus on the implications of wine ageing on its sensory aspects, something that seems particularly important for wineries. In this sense, Temporal-Check-All-That-Apply (TCATA) type of methodologies may be of great use (e.g., [131]).

Finally, gastrophysics, which combines gastronomy and psychophysics in order to understand what happens in the diner's mind, in relationship to what happens in their mouths, may also be of relevance when designing multisensory wine experiences [132]. Here, the focus would be on the science of the mind of the consumer, rather than in the science present in culinary/cooking process [133]. To date, much of the gastrophysics research has focused less on the associations between the attributes of food and perception, but instead on "the everything else" that may influence multisensory food/beverage experiences, where wine should not be an exception. For example, this includes the further understanding of the role of wine glassware (as already discussed above), but at the same time also the role of plate-ware, cutlery, multisensory atmospheres, brand touchpoints, 
food aesthetics, as well many other extrinsic factors that may be part of a multisensory wine experience [132]. Gastrophysics aims to be regarded as a broader analysis, from internal states, to cultural influences, on food and drink experiences [134,135].

Author Contributions: Conceptualization, R.C, F.R.-C. and P.R.; methodology, R.C., F.R.-C. and P.R.; formal analysis, F.R.-C. and R.C.; writing-original draft preparation, R.C. and F.R.-C.; writingreview and editing, R.C. and F.R.-C.; supervision, F.R.-C.; funding acquisition, P.R. All authors have read and agreed to the published version of the manuscript.

Funding: P.R is supported by University of Bari internal funding scheme; F.R.-C. was supported by Universidad de los Andes internal funding scheme (FAPA n.32/PR.3.2018.4927).

Institutional Review Board Statement: Not applicable.

Informed Consent Statement: Not applicable.

Acknowledgments: The authors would like to sincerely thank Charles Spence (Crossmodal Laboratory, University of Oxford), and Carlos Velasco (Centre for Multisensory marketing-CMM, BI Norway), for insightful suggestions during a part of this process.

Conflicts of Interest: The authors declare no conflict of interest.

\section{References}

1. Shepherd, G.M. Neurogastronomy: How the Brain Creates Flavor and Why It Matters; Columbia University Press: New York, NY, USA, 2011.

2. Auvray, M.; Spence, C. The multisensory perception of flavor. Conscious Cogn. 2008, 17, 1016-1031. [CrossRef]

3. Slocombe, B.G.; Carmichael, D.A.; Simner, J. Cross-modal tactile-taste interactions in food evaluations. Neuropsychologia 2016, 88, 58-64. [CrossRef]

4. Stillman, J.A. Gustation: Intersensory experience par excellence. Perception 2002, 31, 1491-1500. [CrossRef] [PubMed]

5. Xiao, X.; Dupuis-Roy, N.; Jiang, J.; Du, X.; Zhang, M.; Zhang, Q. The neural basis of taste-visual modal conflict control in appetitive and aversive gustatory context. Neuroscience 2018, 372, 154-160. [CrossRef] [PubMed]

6. Small, D.M. Flavor is in the brain. Physiol. Behav. 2012, 107, 540-552. [CrossRef] [PubMed]

7. Spence, C. Just how much of what we taste derives from the sense of smell? Flavour 2015, 4, 30. [CrossRef]

8. Jung, J.; Mittal, V. Political Identity and the Consumer Journey: A Research Review. J. Retail. 2020, 96, 55-73. [CrossRef]

9. Shavitt, S.; Barnes, A.J. Culture and the Consumer Journey. J. Retail. 2020, 96, 40-54. [CrossRef]

10. Lemon, K.N.; Verhoef, P.C. Understanding Customer Experience Throughout the Customer Journey. J. Mark. 2016, 80, 69-96. [CrossRef]

11. Delwiche, J. The impact of perceptual interactions on perceived flavor. Food Qual. Prefer. 2004, 15, 137-146. [CrossRef]

12. Small, D.M.; Prescott, J. Odor/taste integration and the perception of flavor. Exp. Brain Res. 2005, 166, 345-357. [CrossRef] [PubMed]

13. Spence, C. Multisensory flavour perception. Cell 2015, 161, 24-35. [CrossRef]

14. Delwiche, J. Are there 'basic' tastes? Trends Food Sci. Technol. 1996, 7, 411-415. [CrossRef]

15. Prescott, J. Multisensory processes in flavour perception and their influence on food choice. Curr. Opin. Food Sci. 2015, 3, 47-52. [CrossRef]

16. Spence, C. Eating with our ears: Assessing the importance of the sounds of consumption on our perception and enjoyment of multisensory flavor experiences. Flavour 2015, 4, 3. [CrossRef]

17. Calvo-Porral, C.; Lévy-Mangin, J.P.; Ruiz-Vega, A. An emotion-based typology of wine consumers. Food Qual. Prefer. 2020, 79, 103777. [CrossRef]

18. Arvisenet, G.; Guichard, E.; Ballester, J. Taste-aroma interaction in model wines: Effect of training and expertise. Food Qual. Prefer. 2016, 52, 211-221. [CrossRef]

19. Rolls, E.T.; Baylis, L.L. Gustatory, olfactory, and visual convergence within the primate orbitofrontal cortex. J. Neurosci. 1994, 14, 5437-5452. [CrossRef]

20. Ventura, A.K.; Worobey, J. Early influences on the development of food preferences. Curr. Biol. 2013, 23, R401-R408. [CrossRef]

21. Havermans, R.C.; Hermanns, J.; Jansen, A. Eating without a nose: Olfactory dysfunction and sensory-specific satiety. Chem. Senses 2010, 35, 735-741. [CrossRef] [PubMed]

22. Yeomans, M.R. Olfactory influences on appetite and satiety in humans. Physiol. Behav. 2006, 87, 800-804. [CrossRef]

23. Croijmans, I.; Majid, A. Not all flavor expertise is equal: The language of wine and coffee experts. PLoS ONE 2016, 11, e0155845. [CrossRef]

24. Shepherd, G.M. Neuroenology: How the brain creates the taste of wine. Flavour 2015, 4, 19. [CrossRef] 
25. Saenz-Navajas, M.P.; Campo, E.; Avizcuri, J.M.; Valentin, D.; Fernandez-Zurbano, P.; Ferreira, V. Contribution of non-volatile and aroma fractions to in mouth sensory properties of red wines: Wine reconstitution strategies and sensory sorting task. Anal. Chim. Acta 2012, 732, 64-72. [CrossRef]

26. Morrot, G.; Brochet, F.; Dubourdieu, D. The color of odors. Brain Lang. 2001, 79, 309-320. [CrossRef]

27. Ballester, J.; Abdi, H.; Langlois, J.; Peyron, D.; Valentin, D. The odor of colors: Can wine experts and novices distinguish the odors of white, red, and rosé wines? Chemosens. Percept. 2009, 2, 203-213. [CrossRef]

28. Wang, Q.J.; Spence, C. Drinking through rosé-coloured glasses: Influence of wine colour on the perception of aroma and flavour in wine experts and novices. Food Res. Int. 2019, 126, 108678. [CrossRef] [PubMed]

29. Parr, W.V.; White, K.G.; Heatherbell, D.A. The nose knows: Influence of color on perception of wine aroma. J. Wine Res. 2003, 14, 79-101. [CrossRef]

30. Heatherly, M.; Dein, M.; Munafo, J.P.; Luckett, C.R. Crossmodal correspondence between color, shapes, and wine odors. Food Qual. Prefer. 2019, 71, 395-405. [CrossRef]

31. Hanson-Vaux, G.; Crisinel, A.-S.; Spence, C. Smelling shapes: Crossmodal correspondences between odors and shapes. Chem. Senses 2013, 38, 161-166. [CrossRef] [PubMed]

32. Hummel, T.; Delwiche, J.F.; Schmidt, C.; Hüttenbrink, K.B. Effects of the form of glasses on the perception of wine flavors: A study in untrained subjects. Appetite 2003, 41, 197-202. [CrossRef]

33. Cliff, M.A. Influence of wine glass shape on perceived aroma and color intensity in wines. J. Wine Res. 2001, 12, 39-46. [CrossRef]

34. Delwiche, J.F.; Pelchat, M.L. Influence of glass shape on wine aroma. J. Sens. Stud. 2002, 17, 19-28. [CrossRef]

35. Hüttenbrink, K.B.; Schmidt, C.; Delwiche, J.F.; Hummel, T. Der genuss von rotwein wird durch die form des glases beeinflusst [The enjoyment of red wine is influenced by the shape of glass]. Laryngorhinootologie 2001, 80, 96-100. [CrossRef] [PubMed]

36. Gram-Hanssen, A.; Bøge Paulsen, C.; Rosenberg, J. Flavor perception of wine is unchanged during commercial flight: A comparative field study. F1000Research 2020, 9, 597. [CrossRef]

37. Kuehn, M.; Welsch, H.; Zahnert, T.; Hummel, T. Changes of pressure and humidity affect olfactory function. Eur. Arch. Oto-Rhino-Laryngol. 2008, 265, 299-302. [CrossRef]

38. Köhler, W. Gestalt Psychology; Liveright: New York, NY, USA, 1929.

39. Reinoso Carvalho, F.; Wang, Q.J.; van Ee, R.; Persoone, D.; Spence, C. Smooth operator: Music modulates the perceived creaminess, sweetness, and bitterness of chocolate. Appetite 2017, 108, 383-390. [CrossRef]

40. Parpinello, G.P.; Meglioli, M.; Ricci, A.; Versari, A. Effect of different glass shapes and size on the time course of dissolved oxygen in wines during simulated tasting. Beverages 2018, 4, 3 .

41. Cheskin, L. Marketing Success: How to Achieve It; Cahners Books: Chicago, IL, USA, 1972.

42. Spence, C.; Gallace, A. Multisensory design: Reaching out to touch the consumer. Psychol. Mark. 2011, 28, 267-308. [CrossRef]

43. Fenko, A.; Schifferstein, H.N.; Hekkert, P. Shifts in sensory dominance between various stages of user-product interactions. Appl. Ergon. 2010, 41, 34-40. [CrossRef] [PubMed]

44. Murray, M.M.; Eardley, A.F.; Edginton, T.; Oyekan, R.; Smyth, E.; Matusz, P.J. Sensory dominance and multisensory integration as screening tools in aging. Sci. Rep. 2018, 8, 1-11. [CrossRef]

45. Colavita, F.B. Human sensory dominance. Percept. Psychophysiol. 1974, 16, 409-412. [CrossRef]

46. Mroczko-Wasowicz, A. The unity and complexity of flavour perception: Multisensory phenomenology and processing in human-food interactions. In Proceedings of the 1st Workshop on Multi-Sensorial Approaches to Human-Food Interaction, Tokyo, Japan, 16 November 2016; pp. 1-4.

47. Zellner, D.A.; Durlach, P. Effect of color on expected and experienced refreshment, intensity, and liking of beverages. Am. J. Psychol. 2003, 116, 633-647. [CrossRef] [PubMed]

48. Pangborn, R.M.; Berg, H.W.; Hansen, B. The influence of color on discrimination of sweetness in dry table-wine. Am. J. Psychol. 1963, 76, 492-495. [CrossRef]

49. Delwiche, J.F. Impact of color on perceived wine flavor. Foods Food Ingred. 2003, 208, 349-352.

50. Dooley, L.M.; Threlfall, R.T.; Meullenet, J.F.; Howard, L.R. Compositional and sensory impacts of blending red wine varietals. Am. J. Enol. Vitic. 2012, 63, 241-250. [CrossRef]

51. Valentin, D.; Parr, W.V.; Peyron, D.; Grose, C.; Ballester, J. Color as a driver of Pinot noir wine quality judgments: An investigation involving French and New Zealand wine professionals. Food Qual. Prefer. 2016, 48A, 251-261. [CrossRef]

52. Wang, Q.J.; Spence, C. Is complexity worth paying for? Investigating the perception of wine complexity for single varietal and blended wines in consumers and experts. Aust. J. Grape Wine Res. 2019, 25, 243-251. [CrossRef]

53. Lick, E.; König, B.; Kpossa, M.R.; Buller, V. Sensory expectations generated by colors of red wine labels. J. Retail. Consum. Serv. 2017, 37, 146-158. [CrossRef]

54. Shankar, M.U.; Levitan, C.A.; Spence, C. Grape expectations: The role of cognitive influences in color-flavor interactions. Conscious. Cogn. 2010, 19, 380-390. [CrossRef] [PubMed]

55. Oberfeld, D.; Hecht, H.; Allendorf, U.; Wickelmaier, F. Ambient lighting modifies the flavor of wine. J. Sens. Stud. 2009, 24, 797-832. [CrossRef]

56. Hannum, M.; Forzley, S.; Popper, R.; Simons, C.T. Does environment matter? Assessments of wine in traditional booths compared to an immersive and actual wine bar. Food Qual. Prefer. 2019, 76, 100-108. [CrossRef] 
57. Jiang, W.; Niimi, J.; Ristic, R.; Bastian, S.E.P. Effects of immersive context and wine flavor on consumer wine flavor perception and elicited emotions. Am. J. Enol. Vitic. 2017, 68, 1-10. [CrossRef]

58. Russell, K.; Zivanovic, S.; Morris, W.C.; Penfield, M.; Weiss, J. Polyphenolic compounds and perception of Merlot wine. J. Food Qual. 2005, 28, 377-385. [CrossRef]

59. Spence, C.; Wan, X. Beverage perception and consumption: The influence of the container on the perception of the contents. Food Qual. Prefer. 2015, 39, 131-140. [CrossRef]

60. Vilanova, M.; Vidal, P.; Cortés, S. Effect of the glass shape on flavor perception of toasted wine from Ribeiro (NW Spain). J. Sens. Stud. 2008, 23, 114-124. [CrossRef]

61. Wan, X.; Zhou, X.; Woods, A.T.; Spence, C. Influence of the glassware on the perception of alcoholic drinks. Food Qual. Prefer. 2015, 44, 101-110. [CrossRef]

62. Raudenbush, B.; Meyer, B.; Eppich, W.; Corley, N.; Petterson, S. Ratings of pleasantness and intensity for beverages served in containers congruent and incongruent with expectancy. Percept. Mot. Ski. 2015, 94, 671-674. [CrossRef]

63. Pechey, R.; Couturier, D.L.; Hollands, G.J.; Mantzari, E.; Munafò, M.R.; Marteau, T.M. Does wine glass size influence sales for on-site consumption? A multiple treatment reversal design. BMC Public Health 2016, 16, 390. [CrossRef] [PubMed]

64. Reynolds, D.; Rahma, I.; Bernard, S.; Holbrook, A. What effect does wine bottle closure type have on perceptions of wine attributes? Int. J. Hosp. Manag. 2018, 75, 171-178. [CrossRef]

65. Barber, N.; Taylor, D.C.; Dodd, T. The importance of wine bottle closures in retail purchase decisions of consumers. J. Hosp. Mark. Manag. 2009, 18, 597-614. [CrossRef]

66. Marin, A.B.; Jorgensen, E.M.; Kennedy, J.A.; Ferrier, J. Effects of bottle closure type on consumer perceptions of wine quality. Am. J. Enol. Vitic. 2007, 58, 182-191.

67. Marin, A.B.; Durham, C.A. Effects of wine bottle closure type on consumer purchase intent and price expectation. Am. J. Enol. Vitic. 2007, 58, 192-201.

68. Spence, C. Crystal clear or gobbletigook? World Fine Wine 2011, 33, 96-101.

69. Spence, C.; Parise, C.V. The cognitive neuroscience of crossmodal correspondences. i-Perception 2012, 3, 410-412. [CrossRef] [PubMed]

70. Doehrmann, O.; Naumer, M.J. Semantics and the multisensory brain: How meaning modulates processes of audio-visual integration. Brain Res. 2008, 1242, 136-150. [CrossRef]

71. Mastroberardino, S.; Santangelo, V.; Macaluso, E. Crossmodal semantic congruence can affect visuo-spatial processing and activity of the fronto-parietal attention networks. Front. Integr. Neurosci. 2015, 9, 45. [CrossRef]

72. Mroczko-Wąsowicz, A.; Nikolić, D. Semantic mechanisms may be responsible for developing synesthesia. Front. Hum. Neurosci. 2014, 8, 509 .

73. Schifferstein, H.N.J. The drinking experience: Cup or content? Food Qual. Exp. 2009, 20, 268-276. [CrossRef]

74. Krishna, A.; Morrin, M. Does touch affect taste? The perceptual transfer of product container haptic cues. J. Consum. Res. 2008, 34, 807-818. [CrossRef]

75. Piqueras-Fiszman, B.; Spence, C. The weight of the bottle as a possible extrinsic cue with which to estimate the price (and quality) of the wine? Observed correlations. Food Qual. Prefer. 2012, 25, 41-45. [CrossRef]

76. Wang, Q.J.; Spence, C. A smooth wine? Haptic influences on wine evaluation. Int. J. Gastron. Food Sci. 2018, 14, 9-13. [CrossRef]

77. Etzi, R.; Spence, C.; Gallace, A. Textures that we like to touch: An experimental study of aesthetic preferences for tactile stimuli. Conscious. Cogn. 2014, 29, 178-188. [CrossRef]

78. Jackson, R.S. Wine Tasting: A Professional Handbook; Academic Press: Burlington, MA, USA, 2009.

79. Jones, P.R.; Gawel, R.; Francis, I.L.; Waters, E.J. The influence of interactions between major white wine components on the aroma, flavor and texture of model white wine. Food Qual. Prefer. 2008, 19, 596-607. [CrossRef]

80. Ross, C.F.; Weller, K. Effect of serving temperature on the sensory attributes of red and white wines. J. Sens. Stud. 2008, 23, 398-416. [CrossRef]

81. Cliff, M.A.; King, M.C. Influence of serving temperature and wine type on perception of ethyl acetate and 4-ethyl phenol in wine. J. Wine Res. 2009, 20, 45-52. [CrossRef]

82. Niimi, J.; Danner, L.; Li, L.; Bossan, H.; Bastian, S.E.P. Wine consumers' subjective responses to wine mouthfeel and understanding of wine body. Food Res. Int. 2017, 99, 115-122. [CrossRef] [PubMed]

83. Laguna, L.; Bartolomé, B.; Moreno-Arribas, M.V. Mouthfeel perception of wine: Oral physiology, components and instrumental characterization. Trends Food Sci. Technol. 2017, 59, 49-59. [CrossRef]

84. Runnebaum, R.C.; Boulton, R.B.; Powell, R.L.; Heymann, H. Key constituents affecting wine body-An exploratory study. J. Sens. Stud. 2011, 26, 62-70. [CrossRef]

85. Spence, C. Sound: The forgotten flavor sense. In Multisensory Flavor Perception. From Fundamental Neuroscience through to the Marketplace; Woodhead Publishing Series in Food Science; Technology and Nutrition: Cambridge, UK, 2016; Chapter 5; pp. 81-105.

86. Spence, C.; Reinoso-Carvalho, F.; Velasco, C.; Wang, Q.C. Extrinsic auditory contributions to food perception; consumer behaviour: An interdisciplinary review. Multisens. Res. 2019, 32, 275-318. [CrossRef]

87. Spence, C. Wine psychology: Basic and applied. Cogn. Res. Princ. Implic. 2020, 5, 1-18. [CrossRef] [PubMed]

88. Areni, C.S.; Kim, D. The influence of background music on shopping behavior: Classical versus top-forty music in a wine store. ACR N. Am. Adv. 1993, 20, 336-340. 
89. North, A.C.; Hargreaves, D.J.; McKendrick, J. In-store music affects product choice. Nature 1997, 390, 132. [CrossRef]

90. North, A.C.; Hargreaves, D.J.; McKendrick, J. The influence of in-store music on wine selections. J. Appl. Psychol. 1999, 84, 271-276. [CrossRef]

91. De Luca, M.; Campo, R.; Lee, R. Mozart or pop music? Effects of background music on wine consumers. Int. J. Wine Bus. Res. 2019, 41, 406-419. [CrossRef]

92. Mesz, B.; Herzog, K.; Cruz Amusategui, J.; Samaruga, L.; Tedesco, S. Let's drink this song together: Interactive taste-sound systems. In Proceedings of the MHFI 2017: 2nd ACM SIGCHI International Workshop on Multisensory Approaches to Human-Food Interaction, Glasgow, UK, 13 November 2017.

93. North, A.C. The effect of background music on the taste of wine. Br. J. Psychol. 2012, 103, 293-301. [CrossRef]

94. Spence, C.; Velasco, C.; Knoeferle, K. A large sample study on the influence of the multisensory environment on the wine drinking experience. Flavour 2014, 3, 8. [CrossRef]

95. Spence, C.; Wang, Q.J. Wine and music (I): On the crossmodal matching of wine and music. Flavour 2015, 4, 34. [CrossRef]

96. Spence, C.; Wang, Q.J. Wine and music (II): Can you taste the music? Modulating the experience of wine through music and sound. Flavour 2015, 4, 33. [CrossRef]

97. Spence, C.; Wang, Q.J. Wine and music (III): So what if music influences the taste of the wine? Flavour 2015, 4, 36. [CrossRef]

98. Spence, C.; Richards, L.; Kjellin, E.; Huhnt, A.-M.; Daskal, V.; Scheybeler, A.; Velasco, C.; Deroy, O. Looking for crossmodal correspondences between classical music and fine wine. Flavour 2013, 2, 29. [CrossRef]

99. Wang, Q.J.; Spence, C. Assessing the effect of musical congruency on wine tasting in a live performance setting. i-Perception 2015, 6, 1-13. [CrossRef] [PubMed]

100. Wang, Q.J.; Spence, C. Assessing the influence of music on wine perception among wine professionals. Food Sci. Nutr. 2018, 6, 295-301. [CrossRef]

101. Reinoso-Carvalho, F.; Gunn, L.; Molina, G.; Narumi, T.; Spence, C.; Suzuki, Y.; ter Horst, E.; Wagemans, J. A sprinkle of emotions vs. a pinch of crossmodality: Towards globally meaningful sonic seasoning strategies for enhanced multisensory tasting experiences. J. Bus. Res. 2020, 117, 389-399. [CrossRef]

102. Spence, C. Sonic seasoning. In Audio Branding: Using Sound to Build Your Brand; Minsky, L., Fahey, C., Eds.; Kogan Page: London, UK, 2017; pp. 52-58.

103. Crisinel, A.-S.; Cosser, S.; King, S.; Jones, R.; Petrie, J.; Spence, C. A bittersweet symphony: Systematically modulating the taste of food by changing the sonic properties of the soundtrack playing in the background. Food Qual. Prefer. 2012, 24, 201-204. [CrossRef]

104. Reinoso-Carvalho, F.; Dakduk, S.; Wagemans, J.; Spence, C. Not just another pint! The role of emotion induced by music on the consumer's tasting experience. Multisens. Res. 2019, 32, 367-400. [CrossRef]

105. Burzynska, J.; Wang, Q.J.; Spence, C.; Bastian, S.E.P. Taste the bass: Low frequencies increase the perception of body and aromatic intensity in red wine. Multisens. Res. 2019, 32, 429-454. [CrossRef]

106. Wang, Q.J.; Mesz, B.; Spence, C. Assessing the impact of music on basic taste perception using time intensity analysis. In Proceedings of the MHFI 2017: 2nd ACM SIGCHI International Workshop on Multisensory Approaches to Human-Food Interaction, Glasgow, UK, 13 November 2017; pp. 18-22.

107. Spence, C.; Wang, Q.J. Assessing the impact of closure type on wine ratings and mood. Beverages 2017, 3, 52. [CrossRef]

108. Malhotra, N.K. Information and sensory overload. Information and sensory overload in psychology and marketing. Psychol. Mark. 1984, 1, 9-21. [CrossRef]

109. Bravo-Moncayo, L.; Reinoso-Carvalho, F.; Velasco, C. The effects of noise control in coffee tasting experiences. Food Qual. Prefer. 2020. [CrossRef]

110. Spence, C. Food and beverage flavour pairing: A critical review of the literature. Food Res. Int. 2020, 133, 109124. [CrossRef]

111. Spence, C.; Wang, Q.J. What does the term complexity mean in the world of wine? Int. J. Gastron. Food Sci. 2018, 14, 45-54. [CrossRef]

112. Spence, C.; Wang, Q.J. On the meaning(s) of perceived complexity in the chemical senses. Chem. Senses 2018, 43, 451-461. [CrossRef] [PubMed]

113. Wang, Q.J.; Spence, C. Wine complexity: An empirical investigation. Food Qual. Prefer. 2018, 68, 238-244. [CrossRef]

114. Nygren, I.T.; Gustafsson, I.-B.; Haglund, Å.; Johansson, L.; Noble, A.C. Flavor changes produced by wine and food interactions: Chardonnay wine and Hollandaise sauce. J. Sens. Stud. 2001, 16, 461-470. [CrossRef]

115. Nygren, I.T.; Gustafsson, I.-B.; Johansson, L. Perceived flavor changes in white wine after tasting blue mould cheese. J. Sens. Stud. 2002, 2, 163-171.

116. Nygren, I.T.; Gustafsson, I.-B.; Johansson, L. Perceived flavor changes in blue mould cheese after tasting white wine. J. Sens. Stud. 2003, 3, 143-150.

117. Madrigal-Galan, B.; Heymann, H. Sensory effects of consuming cheese prior to evaluating red wine flavor. Am. J. Enol. Vitic. 2006, 57, 12-22.

118. Harrington, R.J.; Seo, H. The impact of liking of wine and food items on perceptions of wine-food pairing. J. Foodserv. Bus. Res. 2015, 18, 489-501. [CrossRef]

119. Kustos, M.; Heymann, H.; Jeffery, D.W.; Goodman, S.; Bastian, S.E.P. Intertwined: What makes food and wine pairings appropriate? Food Res. Int. 2020, 136, 109463. [CrossRef] 
120. Gunaratne, T.M.; Fuentes, S.; Gunaratne, N.M.; Torrico, D.D.; Gonzalez Viejo, C.; Dunshea, F.R. Physiological responses to basic tastes for sensory evaluation of chocolate using biometric techniques. Foods 2019, 8, 243. [CrossRef]

121. Xu, Y.; Hamid, N.; Shepherd, D.; Kantono, K.; Reay, S.; Martinez, G.; Spence, C. The effects of background soundscapes on the perception of ice cream and on electrophysiological measures. Food Res. Int. 2020, 125, 108564. [CrossRef]

122. Zhao, H.; Huang, F.; Spence, C.; Wan, X. Visual search for wines with a triangle on the label in a virtual store. Front. Psychol. 2017, 8, 2173. [CrossRef] [PubMed]

123. Zhao, H.; Spence, C.; Wan, X. Visual search for triangles in wine labels. In Proceedings of the 1st Workshop on Multi-Sensorial Approaches to Human-Food Interaction, Tokyo, Japan, 16 November 2016; p. 3.

124. Petit, O.; Velasco, C.; Spence, C. Digital sensory marketing: Integrating new technologies into multisensory online experience. J. Interact. Mark. 2019, 45C, 42-61. [CrossRef]

125. Reinoso-Carvalho, F.; Campo, R.; De Luca, M.; Velasco, C. Towards healthier cookie habits: Assessing the role of packaging visual appearance in the expectations for dietary cookies in virtual environment. (Manuscript submitted for publication).

126. Hagmann, D.; Siegrist, M. Nutri-Score, multiple traffic light and incomplete nutrition labelling on food packages: Effects on consumers' accuracy in identifying healthier snack options. Food Qual. Prefer. 2020, 83, 103894. [CrossRef]

127. Miklavec, K.; Pravst, I.; Raats, M.M.; Pohar, J. Front of package symbols as a tool to promote healthier food choices in Slovenia: Accompanying explanatory claim can considerably influence the consumer's preferences. Food Res. Int. 2016, 90, 235-243. [CrossRef] [PubMed]

128. Vith, E.L.; Steenhuis, I.H.; Vlot, J.A.; Wulp, A.; Hogenes, M.G.; Looije, D.H.; Brug, J.; Seidell, J.C. Actual use of a front-of-pack nutrition logo in the supermarket: Consumers' motives in food choice. Public Health Nutr. 2010, 13, 1882-1889. [CrossRef] [PubMed]

129. Saltman, Y.; Johnson, T.; Wilkinson, K.; Bastian, S. Australian wine consumers' acceptance of and attitudes toward the use of additives in wine and food production. Int. J. Wine Res. 2015, 7, 83-92.

130. Rodrigues, H.; Rolaz, J.; Franco-Luesma, E.; Saenz-Navajas, M.P.; Behrens, J.; Valentin, D.; Depretis-Chauvin, N. How the country-of-origin impacts wine traders' mental representation about wines: A study in a world wine trade fair. Food Res. Int. 2020, 137, 109480. [CrossRef]

131. Wang, Q.; Niaura, T.; Kantono, K. How does wine ageing influence perceived complexity? Temporal-Choose-All-That-Apply (TCATA) reveals temporal drivers of complexity in experts and novices. Food Qual. Prefer. 2021, 92, 104230. [CrossRef]

132. Spence, C. Gastrophysics: The New Science of Eating; Penguin: London, UK, 2017.

133. Spence, C.; Youssef, J. Assessing the long-term impact of the molecular gastronomy movement on haute cuisine. Int. J. Gastron. Food Sci. 2018, 14, 35-44. [CrossRef]

134. Laudan, R. Cuisine and Empire: Cooking in World History; University of California Press: Berkeley, CA, USA, 2013.

135. Visser, M. The Rituals of Dinner: The Origins, Evolution, Eccentricities, and Meaning of Table Manners; Penguin Books: London, UK, 1991. 